\title{
Correction to: Disasters and Disaster Risk Management in South Africa
}

\author{
Christina Culwick
}

\section{Correction to:}

Chapter 32 in: J. Knight, C. M. Rogerson (eds.), The Geography of South Africa, World Regional Geography Book Series, https://doi.org/10.1007/978-3-319-94974-1_32

Belated correction received from the corresponding author, Christina Culwick, of Chapter 32 in regards to the expansion of affiliation. The correct affiliation has now been added in the Table of Contents and in the chapter which reads as follows:

Gauteng City-Region Observatory, a partnership between the University of Johannesburg, the University of the Witwatersrand, Johannesburg, Gauteng Provincial Government and organised local government in Gauteng, Johannesburg, South Africa.

The updated online version of this chapter can be found at https://doi.org/10.1007/978-3-319-94974-1_32 